The University of Maine

\title{
DigitalCommons@UMaine
}

University of Maine Office of Research and

Sponsored Programs: Grant Reports

Special Collections

$11-23-2010$

\section{University of Maine Integrated Forest Product Refinery (IFPR) Technology Research}

Hemant P. Pendse

Principal Investigator; University of Maine, Orono, pendse@maine.edu

Follow this and additional works at: https://digitalcommons.library.umaine.edu/orsp_reports

Part of the Natural Resources and Conservation Commons, Oil, Gas, and Energy Commons, and the Wood Science and Pulp, Paper Technology Commons

\section{Recommended Citation}

Pendse, Hemant P., "University of Maine Integrated Forest Product Refinery (IFPR) Technology Research" (2010). University of Maine Office of Research and Sponsored Programs: Grant Reports. 26.

https://digitalcommons.library.umaine.edu/orsp_reports/26 
PROJECT TITLE:

Universitv of Maine Integrated Forest Product Refinery (IFPR) Technologv Research

DE-FG02-08ER64635 (09/01/2008 to 08/31/2010)

\section{PRINCIPAL INVESTIGATOR}

Hemant P. Pendse UMaine FBRI Director pendse@maine.edu

\section{EXECUTIVE SUMMARY}

This project supported research on science and technology that forms a basis for integrated forest product refinery for co-production of chemicals, fuels and materials using existing forest products industry infrastructure. Clear systems view of an Integrated Forest Product Refinery (IFPR) allowed development of a compelling business case for a small scale technology demonstration in Old Town $\mathrm{ME}$ for co-production of biofuels using cellulosic sugars along with pulp for the new owners of the facility resulting in an active project on Integrated Bio-Refinery (IBR) at the Old Town Fuel \& Fiber. Work on production of advanced materials from woody biomass has led to active projects in bioplastics and carbon nanofibers. A lease for 40.000 sq. ft. high-bay space has been obtained to establish a Technology Research Center for IFPR technology validation on industrially relevant scale. UMaine forest bioproducts research initiative that began in April 2006 has led to establishment of a formal research institute beginning in March 2010.

November 23, 2010 


\section{YEAR I PROGRESS as of August 31, 2009}

Project contract was put in place on 09/16/2008 with effective date of 09/01/2008.

In early Fall 2008, Forest Bioproducts Research Initiative (FBRI) team organized three new research clusters for this project under led by Profs. Aaron Weiskettle. Anthony Halog, and David Neivandt to focus on:

1. Biomass and Short Rotation Woody Crop potential in Maine

2. Life Cycle Analysis of biofuels from woodchips

3. High value bioproducts from lignin

FBRI Advisory Board meeting held in July 2008 provided guidance for formulation of these clusters.

Specific objectives of the project include:

Objective 1: To analyze "Green Marketing" of a stable forest-based bio-economy built on utilizing sustainable supply of targeted biomass feedstocks. Focus here is on analyzing production of new bioproducts (fuels, chemicals and materials) using life cycle analysis of technological pathways and economic assessment of IFPR business models.

- Objective 2: To research technological pathways for innovative separation of wood components and their conversion into co-products, with focus on selective and controlled extraction of hemicelluloses from wood.

- Objective 3: To develop process models and perform feasibility analysis of 'industry cluster' opportunities to transition existing forest products manufacturing infrastructures into sustainable operations for co-production of fuels and chemicals.

- Milestone 1: Review detail plans and assemble specific multi-disciplinary research clusters focused on the three project objectives (with graduate student and staff support) by December 2008. (ACCOMPLISHED on time)

As a follow up to the announcement of DOE award selection of the Old Town mill conversion to an integrated biorefinery in April 2008, FBRI team worked on analysis of various technology pathways for converting pre-pulping extracts from hardwood feedstocks into advanced biofuels including ethanol, butanol and jet fuel. Additional pathways to utilize cellulosic brownstock for producing chemicals and fuels, instead of market pulp, were also analyzed. Emphasize remains on balanced use of both cellulose and hemicellulose fractions separately to a multi-product portfolio with manufacturing flexibility to adapt to market conditions. This work was key to the due diligence on IFPR implementation plans by the new owners of the Old Town mill. Red Shield Acquisition, LLC (RSA) had acquired the Old town Mill Site in November 2008. via investment funds managed by Patriarch Partners, LLC. This provided focus on conversion of wood extracts and cellulosic brownstock into fuels and chemicals including biobutanol. ethanol, and jet fuel precursors. RSA issued the letter of intent to pursue the Old Town Integrated Biorefinery project with 1 to 1 match with the $\$ 30$ million award from the Department of Energy for co-production of biobutanol and market pulp on February 3.2009 and participated in a due diligence review with DOE at Golden. CO on February 26, 2009. FBRI team worked with LOGOS Technology on finalizing a sub-contract for a LOGOS prime contract from the Defense Advanced Research Projects Agency (DARPA) to produce fully compatible jet fuel from cellulose. IFPR forms a key component of UMaine subcontract from LOGOS. 
- Milestone 2: Developed targeted technology pathways (Objective 2) for selected biomass feedstocks (Objective 1) to guide and focus life cycle analysis and process simulation efforts. It was decided to focus of pre-pulping extraction and use of wood extracts for possible biofuels production, with a possibility of using forest residue as a source of cellulosic sugars in future. Short rotation crops in Maine do not appear to provide significant contribution.

Year I ended with a successful award of $\$ 4.8$ million from the Maine Technology Institute on our project titled "Forest \& Ag Bioproducts Research, Development and Commercialization Facility", which provided for a 40,000 sq. ft. high-bay space for IFPR technology validation on industrially relevant scale which was accepted by the Board of Trustees of the University of Maine System on July 15, 2009. A subcontract for $\$ 250 \mathrm{~K}$ was executed with LOGOS Technologies for wood to jet fuel study with DARPA support on May 27, 2009 with the kick-off meeting taking place on June 1-2, 2009. Both of these projects support further work on cellulosic sugar use for biofuels production.

\section{YEAR II PROGRESS}

Process simulation work on techno-economic analysis of conversion of pre-pulping extracts into ethanol has been refined and is now receiving broad attention. Significant progress has been made on evaluating use of brownstock for levulinic acid production and subsequent upgrading of levulinic acid into jet fuel precursors. Comprative analysis of process alternatives leading to ethanol or butanol using fermentable sugars derived from wood extracts has been performed. Initial work on conversion of wood extracts into mixed acids or specifically lactic acid is encouraging. Lactic acid production from wood extracts can be combined use of potato processing waste feedstock to make a case for PLA manufacture in Maine. More work is underway in cooperation with the Sustainabie Bioplastics Council of Maine with funding from Maine Technology Institute.

Work on development of bioproducts from lignin has shown encouraging results. Prof. Neivandt's group has developed a proprietary process for the creation of carbon nanomaterials from lignin employing commercially available unit operations such as freeze drying in an economically feasible and readily scalable process. A small business in Maine is collaborating on this opportunity.

Lease for 40.000 sq. fl. space was signed with OTFF in March 2010 for renovation. .

- Milestone 3: Integrate results of process simulation work with business economic models and feasibility analysis.

Process simulations and IFPR framework analysis helped making the business case for the new owners of Old Town pulp mill in their deliberations of pursuing co-production of biofuels at a pulp mill. Opportunities for producing butanol and/or ethanol from cellulosic sugars were studied and contrasted. Old Town Pulp Mill gave unprecedented access to UMaine faculty to develop a mill trial plan. This project was very instrumental in helping UMaine to build a partnership with Old Town Fuel \& Fiber (OTFF). Initial analysis is encouraging for production of butanol using wood extracts.

- Milestone 4: Review preliminary results with advisory board members for stakeholder input 
At the July 2010 meeting of FBRI Advisory Board project progress was be reviewed to get stakeholder input. The advisory board endorsed the plan to follow up on advanced materials opportunities in addition to the earlier focus on hemicelluloses extraction of woodchips prior to pulping.

\section{Summary of selected topics covered in this project shows lessons learned new opportunities developed for the Integrated Forest Products Refinery (IFPR).}

Topic 1: Evaluating and estimating productivity of several alternative short-rotation woody crops for biomass production in Maine

Overall, production of biomass with the use of SWRC or perennial grasses like switchgrass is possible in Maine. However, the contribution of SWRC and perennial grasses to the total available biomass pool in Maine is likely to be small because of the limited amount of Jand available for production. the lack of landowner incentive programs, and the relatively low value of biomass. For example, even if all the available land in Maine was converted to high-yielding SWRC or switchgrass. this resource would only contribute $5.7 \%$ of the annual 368 million BTUs consumed in Maine for energy. On the other hand, an important limitation of this analysis was that productivity was estimated using computer simulation models with parameters derived for the performance of a specific genotype at certain location. Future efforts would require establishing trial plantations with both SWRC and perennial grasses present so that the model predictions can be validated and improved.

\section{Topic 2: Use of Pre-extraction Technology to Improve High Yield Pulp Production}

Extent of hemicellulose extraction from wood in the impregnation vessel (IV) is influenced by liquor temperature (T), green liquor charge (GL), liquor to wood ratio (L/W), and residence time $(t)$ in the IV. Effects of temperature and time are often combined in a variable, representing severity, called the $\mathrm{H}$-factor. If wood fibers get degraded during hemicelluloses extraction in the IV the overall pulp yield goes down and resulting pulp quality, particularly tear and tensile strengths, suffers. This can happen due to excessive reduction of the hemicelluloses content of the pulp.

Series of pilot trials were conducted to determine the effect of extraction conditions on pulp yield and physical characteristics of pulp using $900 \mathrm{~g}$ OD woodchips per batch. The results indicate that the high temperatures and low green liquor charge required to get high sugar production, can result in significant reduction of yield and physical properties of pulp. It also showed opportunity to optimize either sugar or acetic acid production rates, if not both at the same time. Loss of pulp yield while using pre-extraction of hemicelluloses remains to be a major concern.

Topic 3: Influence of Extraction Conditions on Mechanical Performance of Oriented Strand Board 
Material for the production of Oriented Strand Board (OSB) was produced at four extraction levels corresponding to measured weight loss values of $3.5,6.1,10.2$, and $11.0 \%$. The first set of 16 pages was produced in May 2009. Control (no weight-loss) and weight loss conditions of 3.5, 6.1, and $10.2 \%$ were used. Panel density ranged from 38 to $42 \mathrm{pcf}$ (dry basis). The panel properties were evaluated using mechanical tests (flexural strength and stiffness in dry and wet condition, internal bond strength in dry and weight condition) and physical tests (density, water absorption ann thickness swell after 24 hours immersion in water).

A second round of panels was made using strands with an $11 \%$ weight loss value and resin levels ranging from $2.5 \%$ to $7.5 \%$. Increasing resin content was found to improve mechanical behavior, which provides a technical approach to offset decreases in mechanical properties resulting from the extraction process.

A third set of panels was manufactured using $11 \%$ weight loss material, $5 \%$ resin level, with the adhesive applied at lower spinning disk rates. Decreases in spinning disk rotation rate from 11,000 to $5,500 \mathrm{rpm}$ was found to steadily decrease flexural strength.

A final set of panels was manufactured in which resin viscosity was increased from $288 \mathrm{Cps}$ to 864 Cps. No significant effect on performance was found.

A interrelationship between extraction weight loss and product density was obtained for eight mechanical and physical properties. The set of process conditions which provided maximum values was significantly different depending upon the property of interest. The values in internal bond strength were found to be decreased to a value below industrial acceptability. This is an indication of poor bond quality. Increasing resin application rates was shown to improve bond quality, while effect of droplet size, and viscosities was not significant.

\section{Topic 4: Carbon Nanomaterials from Lignin}

Usually, lignin is electrospun from an organic solvent to create lignin nanofibers, which are subsequently carbonized. While demonstrating that carbon nanomaterials may be produced from lignin. the use of electrospinning limits the work to the bench scale.

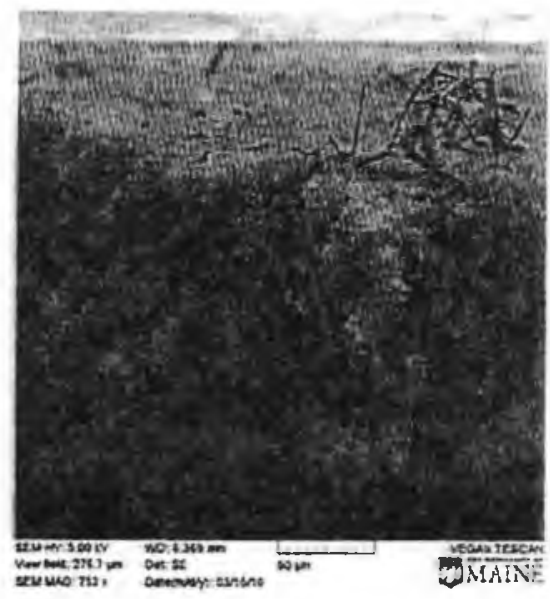

The figure below presents a scanning electron micrograph of a typical carbon nanomaterial produced using freeze drying of aqueous lignin solutions. The process is the subject of a federal contract for scale up and incorporation into photovoltaic materials (US Army Contract: Development of Low Cost Carbon Nanofiber Enhanced Polymer Photovoltaic (PPV) Flexible Fabrics, 01/16/2010-01/15/2011 to Tex Tech Industries, D2 Inline Solutions, and the University of Maine). A provisional patent application (61/253.229) was filed on Oct. 20, 2009. 
Topic 5: Life Cycle Analysis for IFPR pathways

This project supported two Master's theses:

Coupling LCA and GIS for Biodiversity Assessment of Forest-based Bioethanol Production (Mr. Binod Neupane's Thesis); Supported from January 2009 - August 2010. Binod Neupane is expected to graduate on Dec. 2010.

In this study, we quantify life cycle impacts of ethanol, acetic acid, and OSB co-produced in an integrated OSB biorefinery using multiple process scenarios. More specifically, we vary: (i) heat recovery (HR), (ii) presence of an evaporation process to concentrate hemicellulose extract, and (iii) reduced demand for regenerative thermal oxidation emission control technology due to potential volatile organic compound reduction. Then, we compare these impacts to conventionally produced gasoline, acetic acid, and OSB. Finally, we show variation in results caused by allocation method selected (i.e. mass-based versus system boundary expansion). Our findings suggest that the OSB biorefinery has potential to meet $60 \%$ GHG reduction threshold, especially when no evaporation is required to concentrate hemicellulose after $\mathrm{HWE}$ and when heat recovery effectiveness is high. Other impact categorjes (i.e. smog formation, particulate matter formation and terrestrial acidification), however. tend to increase from the baseline scenario. Importantly, we find that system boundary expansion is essential for transparently tracking emissions across all co-products produced in an integrated biorefinery.

Integrating Partial Equilibrium Modeling and Life Cycle Assessment in the Forest Biorefinery Context (Mason Earles Thesis). Supported from January 2010 - August 2010. Mason Earles is expected to graduate on June 2011.

In the RFS2 Impact Analysis, U.S. EPA utilized a dynamic economic (i.e. partial equilibrium) model in conjunction with LCA to evaluate environmental impacts from indirect land use change (ILUC) linked to increased biofuel demand. Using a similar method, we quantify indirect environmental impacts from increased wood demand for bioenergy among forest product sectors. More specifically, we use the U.S. Forest Products Module (USFPM) to estimate substitution and complementarity effects for two alternative bioenergy policy scenarios. The first assumes an unrestrictive definition of renewable biomass, similar to the U.S. Farm Bill, which allows for use of naturally and artificially regenerated forests. The second assumes a restrictive definition. similar to RFS2, which only allow's for the use of artificially regenerated forests. The effects on global production of various forest products and timber supply are then linked to life cycle inventory data to estimate indirect environmental impacts.

\section{CONCLUSION}

This project has helped advance the field of alternative renewable fuels using forest based resources. This can help rural economies, possibly providing regional solutions for the Northern Forest communities. Forest Bioproducts Research Institute (FBRI) at the University of Maine is poised to lead the development of fuels, chemicals, and advanced materials from woody biomass. 